\title{
Erythropoietin in the Locus coeruleus attenuates the ventilatory response to $\mathrm{CO}_{2}$ in rats
}

\author{
Carlos A. Silva ${ }^{\mathrm{a}}$, Mariane C. Vicente ${ }^{\mathrm{a}}$, Luana Tenorio-Lopes ${ }^{\mathrm{b}}$, Jorge Soliz ${ }^{\mathrm{b}, *, 1}$, \\ Luciane H. Gargaglioni ${ }^{\text {a, } 1}$ \\ a Department of Animal Morphology and Physiology, Sao Paulo State University-FCAV, Jaboticabal, SP, Brazil \\ b Centre de Recherche du CHU de Québec, Pavillon St. François d'Assise, Département de Pédiatrie, Faculté de Médecine, Université Laval, Québec, QC, Canada
}

\section{A R T I C L E I N F O}

\section{Article history:}

Received 27 April 2016

Received in revised form 30 September 2016

Accepted 27 October 2016

Available online 3 November 2016

\section{Keywords:}

Erythropoietin

Locus coeruleus

Central chemosensitivity

Hypercapnia

Ventilation

\begin{abstract}
A B S T R A C T
The Locus coeruleus ( $\mathrm{LC}$ ) is a pontine area that contributes to the $\mathrm{CO}_{2} / \mathrm{pH}$ chemosensitivity. $\mathrm{LC}$ cells express erythropoietin (Epo) receptors (EpoR), and Epo in the brainstem is a potent normoxic and hypoxic respiratory stimulant. However, a recent study showed that the intra-cisternal injection (ICI) of Epo antagonist does not alter the hypercapnic ventilatory response in mice. As ICI leads to a widespread dispersal of the product throughout the brainstem, in this work we evaluated the specific impact of Epo in the LCmediated ventilatory response to $\mathrm{CO}_{2}$ (by whole body plethysmography) in juvenile male Wistar rats. Normocapnic and hypercapnic ventilation were evaluated before and after unilateral microinjection of Epo $(1 \mathrm{ng} / 100 \mathrm{~nL})$ into the LC. To evaluate the long-term effect of Epo, the HcVR was re-evaluated $24 \mathrm{~h}$ later. Our results show that Epo attenuates the hypercapnic ventilation. We conclude that Epo in the LC tunes the hypercapnia-induced hyperpnea.
\end{abstract}

(c) 2016 Elsevier B.V. All rights reserved.

\section{Introduction}

The central respiratory chemosensitivity requires sensory cells that detect changes in $\mathrm{PCO}_{2}$ and/or pH (Kumar et al., 2015). The Locus Coeruleus (LC) is considered a central $\mathrm{CO}_{2} / \mathrm{pH}$ chemoreceptor site in mammals (Gargaglioni et al., 2010; Santin and Hartzler, 2013; Taxini et al., 2013). More than $80 \%$ of LC neurons are chemosensitive and respond to hypercapnia with an increased firing rate (Filosa et al., 2002; Oyamada et al., 1998; Pineda and Aghajanian, 1997). Furthermore, the lesion of LC neuroadrenergic neurons leads to a large decrease in the response to $\mathrm{CO}_{2}$ (Biancardi et al., 2008). These facts evidence that the LC nucleus exert a profound effect on the response to hypercapnic ventilation.

Erythropoietin (Epo) and its receptor (EpoR) are widely distributed in the mammalian brain (Rabie and Marti, 2008). EpoR is expressed in neurons, oligodendrocytes, glial cells, and in brain vascular endothelial cells (Brines et al., 2000). Moreover, studies in our group revealed that EpoR is extensively expressed in the brainstem cells, including the LC noradrenergic neurons (Soliz

* Corresponding author at: Faculté de Médecine, Université Laval, Centre de Recherche, HSFA, D0-717, 10, Rue de l'Espinay, Québec, QC G1L 3L5, Canada.

E-mail address: jorge.soliz@crchuq.ulaval.ca (J. Soliz).

1 Both senior authors contributed equally to this work. et al., 2005). Although Epo stimulates the neural control of ventilation during hypoxia (Ballot et al., 2015a; Caravagna et al., 2014, 2015; Caravagna and Soliz, 2015; Khemiri et al., 2011), we reported recently that central chemosensitivity to $\mathrm{CO}_{2}$ is not altered by blocking the cerebral Epo. Specifically, we showed that the soluble EpoR (sEpoR, the natural antagonist of Epo), injected in the brainstem region of adult mice via the cisterna Magna (intracisternal injection, ICI) did not alter the ventilation under normocapnia and hypercapnia (Ballot et al., 2015b). Since a central ICI of sEpoR might activate excitatory and inhibitory areas associated with the ventilatory control, it precludes discriminating the precise impact of Epo in specific respiratory nuclei. In fact, hypoxic studies performed in transgenic mice overexpressing Epo only in the brain showed unaltered, increased, and decreased noradrenaline (NE) content in catecholaminergic cell groups A6, A5 and A2C2 respectively (Soliz et al., 2005). Accordingly, in this study, we tested the hypothesis that Epo modulates the respiratory stimulation elicited by the LC during activation of $\mathrm{CO}_{2}$ chemoreceptor. This hypothesis is also supported by the fact that apart from affecting the hypercapnic ventilation, the LC is also implicated in several brain functions (such as the control of pain, stress and wakefulness, (de Carvalho et al., 2014; Samuels and Szabadi, 2008)), in which Epo is also involved (reviewed in (Wang et al., 2014)). To test this hypothesis, we evaluated the hypercapnic ventilatory response in male rats after receiving a unilateral microinjection of Epo in the LC. Our 


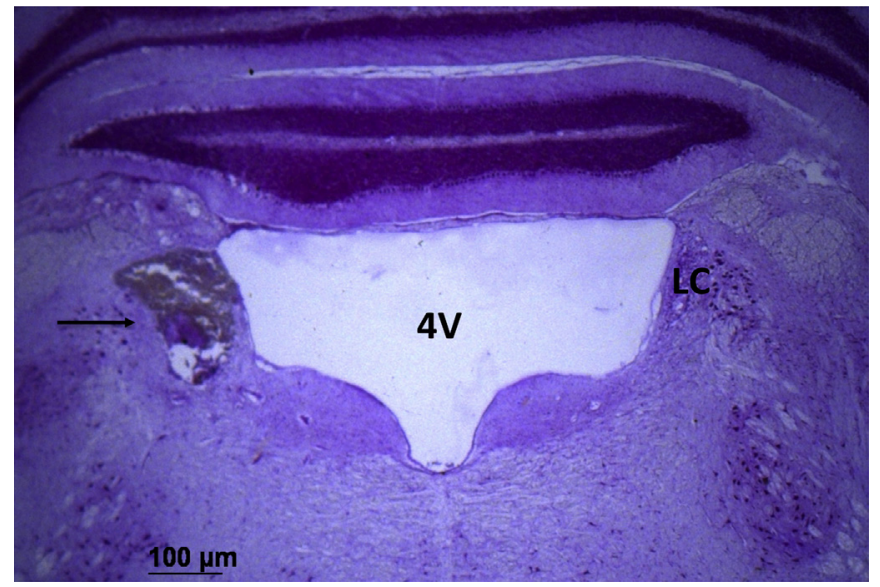

Fig. 1. Representative photomicrograph of unilateral microinjection into the Locus Coeruleus (LC) of rat. A black arrow indicates a typical intra-LC microinjection. $4 \mathrm{~V}$ : fourth ventricle.

results show that Epo in the LC area of rats produces an attenuation of the ventilatory response to $\mathrm{CO}_{2}$. These results suggest that Epo is involved in the LC regulation of the control of breathing.

\section{Material and methods}

\subsection{Animals}

Experiments were performed on male Wistar rats with 6 to 7 weeks of age (average weight of $325 \mathrm{~g}$ ). The animals had free access to water and food and were housed in a temperature-controlled chamber at $24-26^{\circ} \mathrm{C}$ (ALE 9902001; Alesco, Monte Mor, SP, Brazil), with a $12: 12 \mathrm{~h}$ light/dark cycle (lights on at 6:30 a.m.). All experiments were performed between 9:00 am to $5 \mathrm{pm}$. Animal care was carried out in compliance with National Council for the Control of Animal Experimentation (CONCEA-MCT-Brazil) guidelines and was approved by Faculty of Agricultural and Veterinary Sciences and Animal Care and Use Committee (CEUA-FCAV-UNESP-Jaboticabal campus; Protocol n ${ }^{\circ}$ 007094/13).

\subsection{Surgery}

Animals were anaesthetized by the intraperitoneal administration of ketamine $(100 \mathrm{mg} / \mathrm{kg}$; Union National Pharmaceutical Chemistry S/A, Embu-Guaçu, SP, Brazil) and xylazine $(10 \mathrm{mg} / \mathrm{kg}$; Laboratories Calier S/A Barcelona, Spain).

The head and a portion of the abdomen were shaved, and the skin was sterilized with betadine solution and alcohol. Rats were fixed to a Kopf stereotaxic frame and implanted with a stainless steel guide cannula. The guide cannula $(0.7 \mathrm{~mm}$ o.d. and $15 \mathrm{~mm}$ in length) was implanted unilaterally $1 \mathrm{~mm}$ above the $\mathrm{LC}$ region (distance from lambda: anterior: $-3.4 \mathrm{~mm}$; lateral: $-1.2 \mathrm{~mm}$; and dorsal: $-5.8 \mathrm{~mm}$ deep from the skull and inclination of vertical stereotaxic bar at $15^{\circ}$ ), according to Paxinos and Watson atlas (Paxinos and Watson, 1998). The cannula was attached to the bone with stainless steel screws and acrylic cement. A tight fitting styled was kept inside the guide cannula to prevent occlusion. Following the surgery, animals received two doses of enrofloxacin (10 $\mathrm{mg} \mathrm{kg}^{-1}$, intramuscular) and flunixin meglumine $\left(2.5 \mathrm{mg} \mathrm{kg}^{-1}\right.$, subcutaneous) to prevent infection and post-surgical discomfort respectively. The surgical procedures were performed over a period of approximately $40 \mathrm{~min}$. Experiments were initiated six days after surgery.

A day before the experiments a temperature datalogger (SubCue, Calgary, AB, Canada) was implanted in the abdominal cavity through a midline laparotomy for body temperature $\left(\mathrm{Tb}^{\circ}\right)$ measurements. The datalogger was programmed to acquire data every 5 min.

\subsection{Drug and gas mixture}

Recombinant human Epo (rhEpo = $1 \mathrm{ng} / 100 \mathrm{~nL}$; half-life of 4-6 h after administration; CilagAG, Switzerland) was dissolved in artificial cerebral spinal fluid (aCSF; in mM: $14.61 \mathrm{NaCl} ; 4.03 \mathrm{NaHCO}_{3}$, $0.45 \mathrm{KCl}, 0.3 \mathrm{MgSO}_{4}, 0.34 \mathrm{KH}_{2} \mathrm{PO}_{4}, 3.6$ glucose; $0.56 \mathrm{CaCl}_{2}$ ). The gas mixtures used in this study were room air (normocapnia) and a hypercapnic gas mixture $\left(7 \% \mathrm{CO}_{2}, 21 \% \mathrm{O}_{2}\right.$, balance $\mathrm{N}_{2}$; White Martins Gases Industriais Ltda, Sertãozinho, SP, Brazil). The percentage of $\mathrm{CO}_{2}$ was chosen based on previous studies (Biancardi et al., 2008).

\subsection{Determination of the respiratory recording}

Detailed description of whole body plethysmography technique has been previously reported (Vicente et al., 2016). In short, all signals were acquired and recorded on a computer using the data analysis software Acknowledge (v. 4.2.3 data acquisition system, Biopac Systems), and used offline to calculate tidal volume $\left(V_{T}\right)$, respiratory frequency $\left(f_{\mathrm{R}}\right)$, and minute ventilation $\left(\mathrm{V} . \mathrm{e}=\mathrm{V}_{\mathrm{T}} \mathrm{x} f_{\mathrm{R}}\right)$. A volume calibration was performed for each experiment by injecting $1 \mathrm{~mL}$ of air into the animal chamber.

\subsection{Microinjection of Epo and vehicle}

Detailed description of microinjection protocol into the LC has been previously reported (Taxini et al., 2013). In short, microinjections were performed after six days recovery from cannula implantation. A Hamilton syringe (of $5-\mu$ L volume; Reno, NV, USA) was prefilled with Epo or aCSF and then connected to PE-10 tubing and a thin needle injector (33 gauge). Next, the needle injector was inserted into the LC. All microinjections were made with a volume of $100 \mathrm{~nL}$ and were performed over a period of $30 \mathrm{~s}$, with 30 additional sec allowed to elapse before the injection needle was removed from the guide cannula to avoid reflux. All injections were performed using a microinjector machine (model 310, Stoelting Co., IL, USA).

\subsection{Experimental protocol}

Each animal was individually placed in a plexiglass chamber (5 L) maintained at $25^{\circ} \mathrm{C}$ and allowed to move freely while the chamber was flushed with humidified room air. After the animals remained calm for $\sim 30 \mathrm{~min}$, baseline measurements of $\mathrm{V}$. e and $\mathrm{Tb}^{\circ}$ were recorded. Subsequently, rats received a microinjection of vehicle (aCSF) or Epo ( $1 \mathrm{ng} / 100 \mathrm{~nL})$ into the LC. Then the V. e was measured at 5, 10, 15, 20 and 30 min after injection under roomair or the exposure to hypercapnia. Finally, minute ventilation was evaluated after $30 \mathrm{~min}$ of recovery to gas exposure. To test the longterm effect of the Epo microinjection, the HcVR was re-evaluated for a second time, $24 \mathrm{~h}$ later.

\subsection{Statistical analysis}

Values are reported as means \pm SEM. The variances in the $\mathrm{Tb}^{\circ}$ and ventilatory responses to hypercapnia among the groups were analyzed by two- way ANOVA followed by Tukey's test for post hoc comparisons. The significance level was set to $P<0.05$. The statistical analysis was performed using computer software (SIGMA STAT; Systat Software, Point Richmond, CA, USA). 


\section{first day of HcVR}

\section{Vehicle $(n=8)$ \\ Epo $(n=6)$}

\section{normocapnia}

\section{hypercapnia}

a)

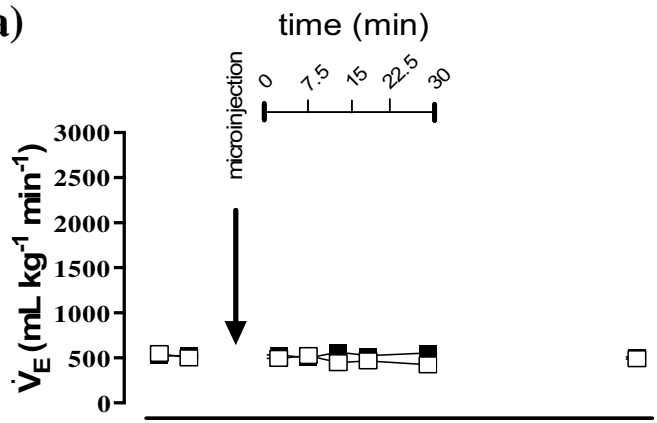

b)

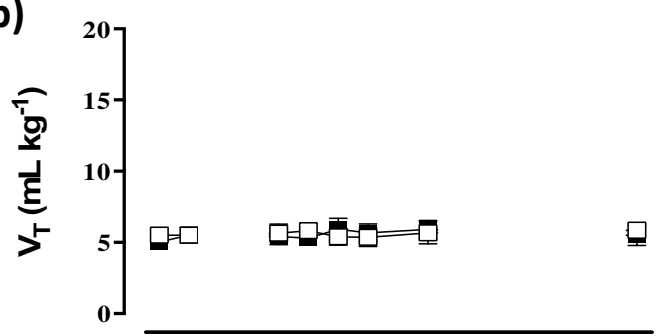

c)



d)



e)

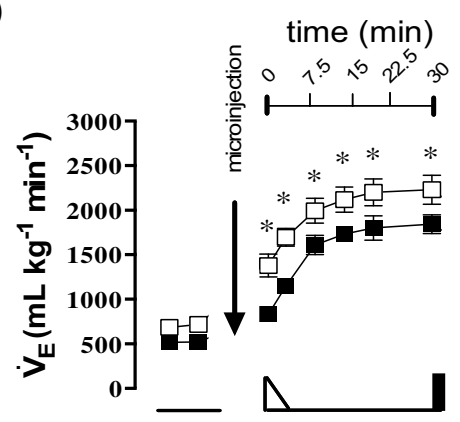

f)



g)

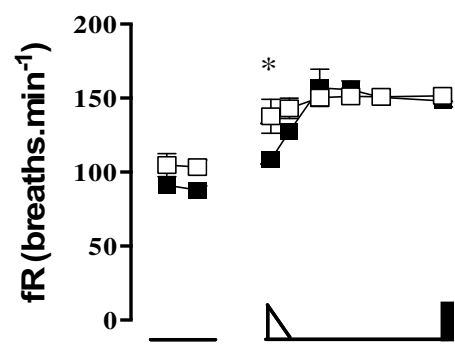

h)

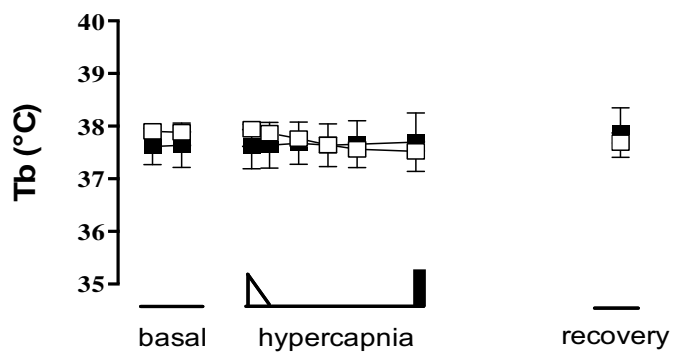

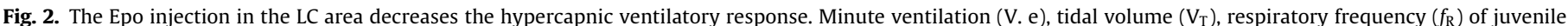

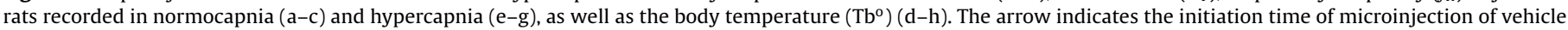

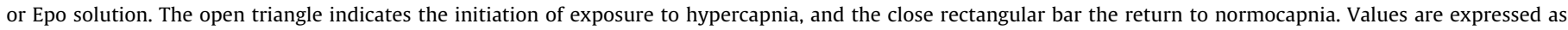
mean \pm S.E.M. Animals per group: vehicle $=8 ; \mathrm{Epo}=6$.

\subsection{Histology}

Upon completion of the experiments, the animals were anaesthetized with ketamine and xylazine and perfused intracardially with saline followed by $10 \%$ formalin solution. A needle injector (19.6 mm long) was inserted through the guide cannula and a $100 \mathrm{~nL}$ microinjection of Evan's blue was performed before fixation. The brain was removed and stored in $10 \%$ formalin for at least 2 days. After fixation, the brainstem was embedded in paraffin, sectioned on a microtome ( $15 \mu \mathrm{m}$ thick coronal sections) and stained by the Nissl method for light microscopy. The region of microinjection was determined using the Paxinos and Watson atlas (Paxinos 


\section{second day of HCVR}

Vehicle $(n=8) \quad-\operatorname{Epo}(n=6)$

\section{normocapnia}

\section{hypercapnia}

a)

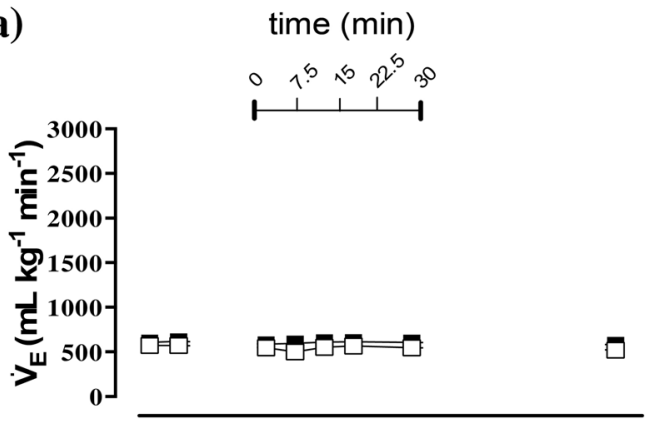

b)

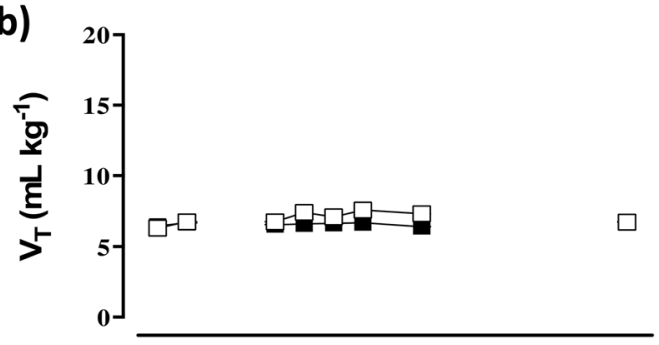

c)

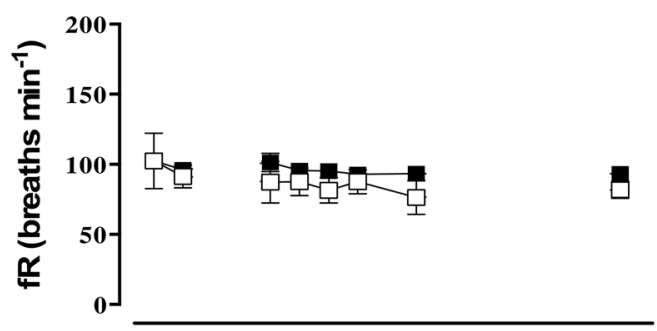

d)

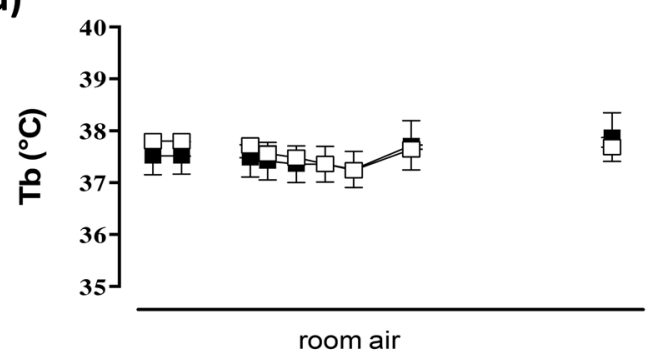

e)

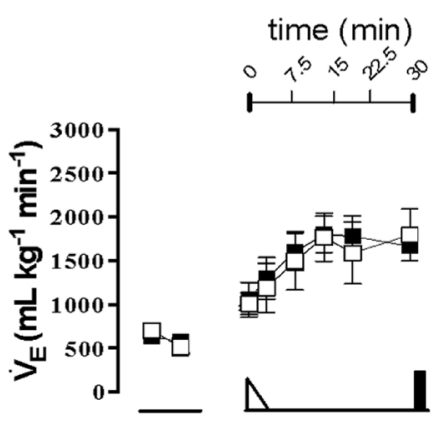

f)

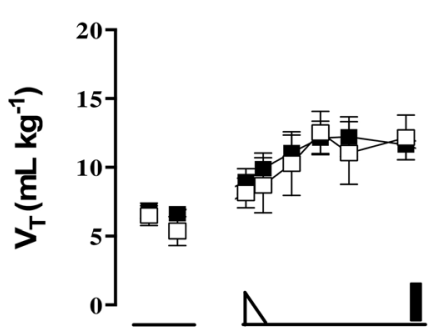

g)



h)

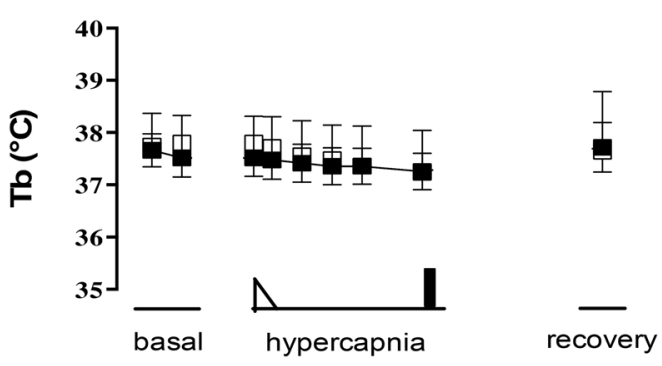






group: vehicle $=5 ;$ Epo $=6$.

and Watson, 1998). Only rats with a confirmed site of microinjection in the LC were considered.

\section{Results}

\subsection{A cannula was unilaterally implanted into the $L C$}

Epo receptors are widespread all long the brainstem regions. As such, these experiments require an accurate cannula implantation into the LC neuroadrenergic region. Fig. 1 shows a representative positive microinjection into the LC. For the results described below, only animals in which the microinjection was proved successful were considered.

\subsection{Epo injection in the LC area attenuated the hypercapnic ventilatory response}

After six days of recovery from cannula implantation, animals were injected with Epo into the LC site. Under normocapnia, Epo showed no effect on minute ventilation (V.e), tidal volume $\left(V_{T}\right)$ and 
first vs. second day of HcVR

\begin{tabular}{lc}
\multicolumn{2}{c}{ hypercapnia } \\
\hline Vehicle & Epo \\
- 1st day & $\square-1$ st day \\
- 2nd day & -2 2nd day
\end{tabular}

a)

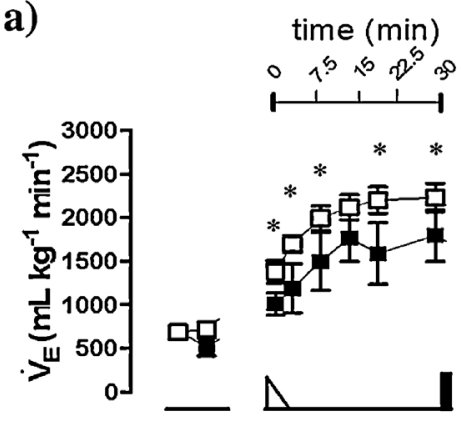

b)

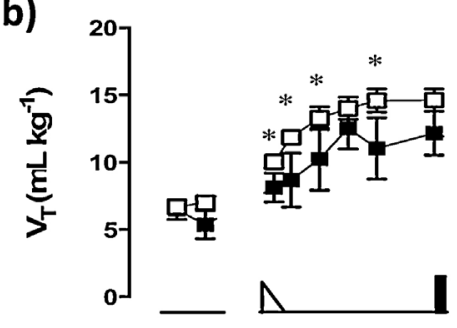

c)

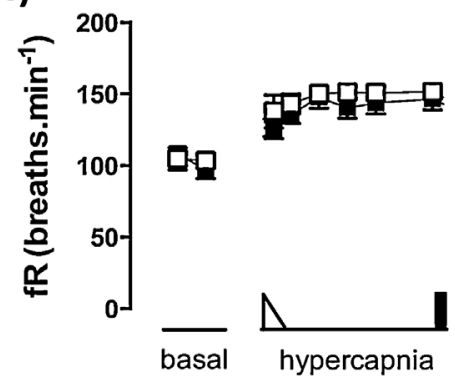

d)

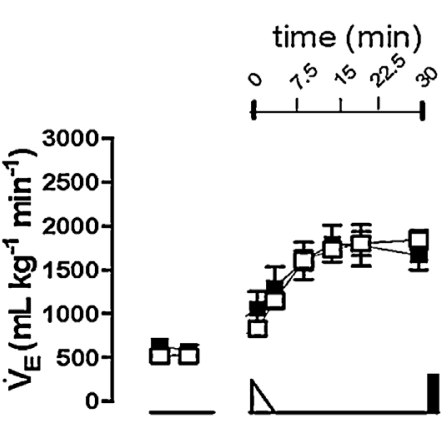

e)

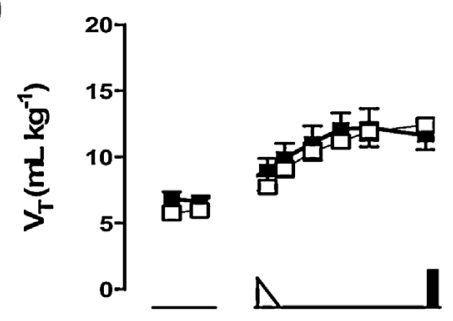

f)

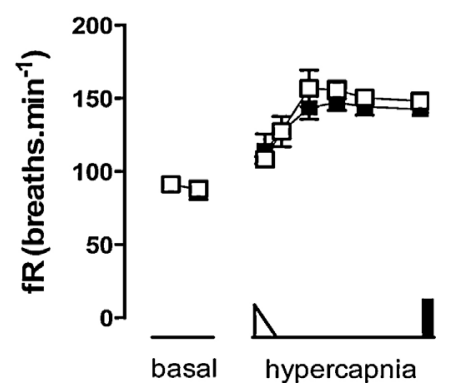

五

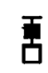

recovery

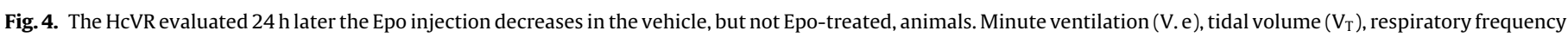


the return to normocapnia. Values are expressed as mean \pm S.E.M.

respiratory frequency $\left(f_{\mathrm{R}}\right)$ (Fig. 2a-c). However, once animals were exposed to hypercapnia, V. e of Epo injected animals was significant lower than control rats (Fig. 2e and Table 1). The decreased hypercapnic ventilation was due to a decreased $V_{\mathrm{T}}$ (Fig. $2 \mathrm{f}$ and Table 1 ), and reduced $f_{\mathrm{R}}$ at $5 \mathrm{~min}$ of exposure (Fig. $2 \mathrm{~g}$ and Table 1 ). The observed alteration of the hypercapnic ventilation was not due to differences in the body temperature (Fig. 2d and h).

\subsection{Epo has a long-term effect in the LC-mediated regulation of hypercapnic ventilation}

To evaluate the long-term effect of Epo in the LC, $24 \mathrm{~h}$ after the first experimentation animals followed a second evaluation of the hypercapnic ventilatory response. As shown in Fig. 3, no differences of normocapnic (Fig. 3a-c) and hypercapnic (Fig. 3e-g and Table 2) Ve, VT and fR were found between control and Epo-treated ani- mals in the second experimentation day. As observed previously, no changes were observed in the body temperature of animals (Fig. 3d and $\mathrm{h}$ ). However, compared to the first experimentation day, control animals showed significantly decreased HcVR in the second day (Fig. 4a). This decreased hypercapnic ventilation was due to reduced VT (Fig. 4b) rather than fR (Fig. 4c). On the contrary, compared to the first experimentation day, Epo-treated rats did not show altered HcVR in the second day (Fig. 3d-f).

\section{Discussion}

In the present study we injected Epo in the LC area of rats to determine whether this hormone specifically acting though this catecholaminergic center impacts the neural control of hypercapnic ventilatory response (HcVR). Interestingly, our results showed that Epo attenuated the LC-mediated hypercapnic ventilation. We 
Table 1

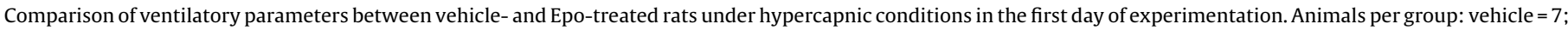
Epo $=6$.

\begin{tabular}{|c|c|c|c|c|c|c|c|c|c|}
\hline \multicolumn{10}{|l|}{1 st day: hypercapnia } \\
\hline \multirow[t]{3}{*}{ Parameter } & & \multirow[t]{3}{*}{ Time (min) } & \multicolumn{4}{|l|}{ Groups } & \multicolumn{3}{|l|}{ Effect } \\
\hline & & & \multicolumn{2}{|l|}{ vehicle } & \multicolumn{2}{|l|}{ Epo } & \multirow[t]{2}{*}{ Group } & \multirow[t]{2}{*}{ Time } & \multirow[t]{2}{*}{ Interaction } \\
\hline & & & mean & SEM & mean & SEM & & & \\
\hline \multirow[t]{9}{*}{ Minute ventilation } & basal & -15 & 687.4 & 50.8 & 518.5 & 21.5 & \multirow[t]{9}{*}{$\begin{array}{l}F=51.01 \\
p<0.0001\end{array}$} & \multirow[t]{9}{*}{$\begin{array}{l}F=74.51 \\
p<0.0001\end{array}$} & \multirow[t]{9}{*}{$\begin{array}{l}F=1.052 \\
p<0.403\end{array}$} \\
\hline & & -10 & 718.7 & 43.7 & 522.2 & 19.6 & & & \\
\hline & HcVR & 2 & 1379.4 & 129.1 & 832.5 & 43.8 & & & \\
\hline & & 5 & 1695.7 & 99.0 & 1151.0 & 62.7 & & & \\
\hline & & 10 & 1995.2 & 140.0 & 1608.3 & 107.4 & & & \\
\hline & & 15 & 2118.7 & 144.1 & 1733.6 & 71.8 & & & \\
\hline & & 20 & 2201.9 & 153.4 & 1801.4 & 137.5 & & & \\
\hline & & 30 & 2228.6 & 162.6 & 1843.5 & 104.7 & & & \\
\hline & recovery & 65 & 602.6 & 37.9 & 464.7 & 31.2 & & & \\
\hline \multirow[t]{9}{*}{ Tidal volume } & basal & -15 & 6.7 & 0.5 & 5.7 & 0.4 & \multirow[t]{9}{*}{$\begin{array}{l}F=52.98 \\
p<0.0001\end{array}$} & \multirow[t]{9}{*}{$\begin{array}{l}F=50.20 \\
p<0.0001\end{array}$} & \multirow[t]{9}{*}{$\begin{array}{l}F=0.96 \\
p<0.467\end{array}$} \\
\hline & & -10 & 7.0 & 0.5 & 5.9 & 0.2 & & & \\
\hline & HcVR & 2 & 10.0 & 0.5 & 7.7 & 0.5 & & & \\
\hline & & 5 & 11.8 & 0.4 & 9.1 & 0.6 & & & \\
\hline & & 10 & 13.3 & 0.8 & 10.4 & 0.6 & & & \\
\hline & & 15 & 13.9 & 0.8 & 11.2 & 0.4 & & & \\
\hline & & 20 & 14.6 & 0.8 & 11.9 & 0.7 & & & \\
\hline & & 30 & 14.6 & 0.8 & 12.4 & 0.5 & & & \\
\hline & recovery & 65 & 7.1 & 0.4 & 6.1 & 0.3 & & & \\
\hline \multirow[t]{10}{*}{ Respiratory frequency } & basal & -15 & 104.8 & 7.8 & 91.2 & 2.9 & \multirow{10}{*}{$\begin{array}{l}F=8.278 \\
p<0.0049\end{array}$} & \multirow{10}{*}{$\begin{array}{l}F=44.82 \\
p<0.0001\end{array}$} & \multirow{10}{*}{$\begin{array}{l}F=1.821 \\
p<0.082\end{array}$} \\
\hline & & & & & & & & & \\
\hline & & -10 & 103.4 & 3.9 & 87.8 & 3.1 & & & \\
\hline & HcVR & 2 & 137.7 & 11.5 & 108.4 & 5.0 & & & \\
\hline & & 5 & 143.0 & 6.9 & 127.4 & 4.3 & & & \\
\hline & & 10 & 150.2 & 3.8 & 156.9 & 12.6 & & & \\
\hline & & 15 & 151.2 & 3.9 & 155.6 & 5.9 & & & \\
\hline & & 20 & 150.8 & 3.5 & 150.4 & 3.7 & & & \\
\hline & & 30 & 151.6 & 3.8 & 148.1 & 5.3 & & & \\
\hline & recovery & 65 & 82.7 & 2.5 & 76.1 & 3.4 & & & \\
\hline
\end{tabular}

concluded that Epo in the LC exerts a modulation of hypercapnic ventilation.

Our experimental protocol was adapted from previous ones (Barros et al., 1998; Pokorski and Antosiewicz, 2010). Despite our system is not equipped to measure metabolism, it was found that the exposure to 2 and $5 \% \mathrm{CO}_{2}$ have no effect on oxygen consumption (Barros et al., 1998; Saiki and Mortola, 1996). In line with these results, our experiments did not show differences in the central body temperature between vehicle and Epo-treated groups. Regarding doses, high amounts of Epo (1000-30000 U/kg) are used for neuroprotection to allow the drug crossing the blood-brain barrier (between 1 and 2\%: 100-300 U/ kg). Keeping in mind that there is about $0.002 \mathrm{UEpo} / \mathrm{mg}$ (Soliz et al., 2007) of brain protein, we conclude that the amount of Epo used in this study $(0.1 \mathrm{UEpo} / \mathrm{Kg}$; $500 \mathrm{ng}=15 \mathrm{U}$ ) is within physiological ranges.

Epo and its receptor (EpoR) are extensively expressed in the mammalian brain (see (Rabie and Marti, 2008)). Suitably, it has been shown that under several types of pathological conditions Epo provides neuroprotection, neurogenesis and repair of the nervous system. More recent investigation revealed that Epo is also implicated in several other important neuronal tasks/issues such as cognitive processing, attention deficit, improvement of mood, fear conditioning, pain relief, and sleep improvement (recently reviewed in (Wang et al., 2014)). However, apart from neuroprotective function involving pathological events, we showed that Epo in the brain plays also an important physiological role by regulating oxygen homeostasis. We observed in rodents (Soliz et al., 2005, 2007) and human (Soliz et al., 2009) that Epo stimulates the ventilatory response when the oxygen supply is lowered. In line with these findings, immunohistochemical analysis revealed that brainstem EpoR is expressed in neurons associated with the regulation of the respiratory rythmogenesis (such as the NTS and the Pre-Bötzinger complex), likewise in catecholaminergic respiratory areas in the pons and the medulla (centers known for shaping the respiratory sensory integration under hypoxia) (Soliz et al., 2005). Moreover, EpoR are densely expressed in the noradrenergic LC cells of mice (Soliz et al., 2005). The LC is the principal site for brain synthesis of noradrenaline (de Carvalho et al., 2014), and its neurons project broadly throughout the neuraxis, including the spinal cord, the brainstem, cerebellum, hypothalamus, and the cortex (Berridge and Waterhouse, 2003; Foote et al., 1983; Swanson and Hartman, 1975). In line with this fact, LC is implicated in several brain functions such as the control of homeostasis, pain and stress (de Carvalho et al., 2014). In addition, the LC is considered a major wakefulness-promoting nucleus, mediating arousal and priming the brain's neurons to be activated by stimuli (Samuels and Szabadi, 2008). As Epo is involved in similar functions (see above), and despite the fact that the intracisternal injection (ICI) of the Epo antagonist (the soluble Epo receptor) in the brainstem of adult mice did not alter the HcVR (Ballot et al., 2015b), it is tempting to hypothesize that Epo has a pivotal role in the general regulation of LC functions. As the central ICI leads to a broad diffusion of the product that, in parallel, should activate and inhibit several areas of the brainstem associated with the ventilatory control, we reasoned that this type of manipulation precludes the discriminating of the impact of Epo in specific respiratory nucleus, such as LC.

The central $\mathrm{CO}_{2}$ respiratory chemoreception is a mechanism by which an increase in $\mathrm{PCO}_{2}$ stimulates breathing as a reflex in order to maintain the arterial $\mathrm{PCO}_{2}$ within a few $\mathrm{mm} \mathrm{Hg}$ of steady state (about $40 \mathrm{~mm} \mathrm{Hg}$ ) (Guyenet et al., 2010). Several experi- 
Table 2

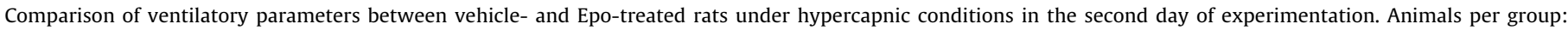
vehicle $=5 ;$ Epo $=6$

\begin{tabular}{|c|c|c|c|c|c|c|c|c|c|}
\hline \multicolumn{10}{|l|}{ 2nd day: hypercapnia } \\
\hline \multirow[t]{3}{*}{ Parameter } & & \multirow[t]{3}{*}{ Time (min) } & \multicolumn{4}{|l|}{ Groups } & \multicolumn{3}{|l|}{ Effect } \\
\hline & & & \multicolumn{2}{|l|}{ vehicle } & \multicolumn{2}{|l|}{ Epo } & \multirow[t]{2}{*}{ Group } & \multirow[t]{2}{*}{ Time } & \multirow[t]{2}{*}{ Interaction } \\
\hline & & & mean & SEM & mean & SEM & & & \\
\hline \multirow[t]{9}{*}{ Minute ventilation } & basal & -15 & 699.9 & 73.9 & 632.7 & 72.2 & \multirow[t]{9}{*}{$\begin{array}{l}F=0.167 \\
p<0.684\end{array}$} & \multirow[t]{9}{*}{$\begin{array}{l}F=11.86 \\
p<0.0001\end{array}$} & \multirow[t]{9}{*}{$\begin{array}{l}F=0.107 \\
p<0.998\end{array}$} \\
\hline & & -10 & 514.9 & 100.9 & 575.8 & 53.4 & & & \\
\hline & HcVR & 2 & 1007.4 & 125.7 & 1055.7 & 198.3 & & & \\
\hline & & 5 & 1187.4 & 281.0 & 1299.6 & 238.4 & & & \\
\hline & & 10 & 1497.5 & 334.9 & 1601.9 & 213.8 & & & \\
\hline & & 15 & 1768.5 & 272.6 & 1801.0 & 209.7 & & & \\
\hline & & 20 & 1588.9 & 353.8 & 1781.3 & 236.7 & & & \\
\hline & & 30 & 1793.1 & 298.2 & 1662.6 & 168.1 & & & \\
\hline & recovery & 65 & 595.7 & 79.8 & 604.8 & 100.8 & & & \\
\hline \multirow[t]{9}{*}{ Tidal volume } & basal & -15 & 6.5 & 0.7 & 6.8 & 0.5 & \multirow[t]{9}{*}{$\begin{array}{l}F=0.594 \\
p<0.443\end{array}$} & \multirow[t]{9}{*}{$\begin{array}{l}F=7.140 \\
p<0.0001\end{array}$} & \multirow[t]{9}{*}{$\begin{array}{l}F=0.179 \\
p<0.993\end{array}$} \\
\hline & & -10 & 5.4 & 1.0 & 6.6 & 0.4 & & & \\
\hline & HcVR & 2 & 8.1 & 1.1 & 8.9 & 0.9 & & & \\
\hline & & 5 & 8.7 & 2.0 & 9.9 & 1.1 & & & \\
\hline & & 10 & 10.2 & 2.3 & 11.1 & 1.3 & & & \\
\hline & & 15 & 12.5 & 1.5 & 12.1 & 1.2 & & & \\
\hline & & 20 & 11.0 & 2.3 & 12.2 & 1.4 & & & \\
\hline & & 30 & 12.1 & 1.6 & 11.6 & 1.1 & & & \\
\hline & recovery & 65 & 7.21 & 0.6 & 6.6 & 0.9 & & & \\
\hline \multirow[t]{10}{*}{ Respiratory frequency } & basal & -15 & 108.4 & 3.9 & 91.4 & 3.9 & \multirow{10}{*}{$\begin{array}{l}F=1.269 \\
p<0.263\end{array}$} & \multirow{10}{*}{$\begin{array}{l}F=20.32 \\
p<0.0001\end{array}$} & \multirow{10}{*}{$\begin{array}{l}F=0.634 \\
p<0.746\end{array}$} \\
\hline & & & & & & & & & \\
\hline & & -10 & 96.7 & 5.8 & 87.1 & 6.3 & & & \\
\hline & HcVR & 2 & 124.6 & 5.7 & 114.3 & 11.4 & & & \\
\hline & & 5 & 135.6 & 6.3 & 127.2 & 10.3 & & & \\
\hline & & 10 & 147.7 & 7.6 & 143.5 & 7.9 & & & \\
\hline & & 15 & 140.3 & 7.3 & 147.2 & 5.4 & & & \\
\hline & & 20 & 143.5 & 7.5 & 144.2 & 5.8 & & & \\
\hline & & 30 & 146.5 & 7.6 & 142.5 & 2.9 & & & \\
\hline & recovery & 65 & 81.9 & 6.6 & 91.7 & 9.5 & & & \\
\hline
\end{tabular}

ments performed in the LC revealed that this area exerts a profound effect on the modulation of the HcVR (Taxini et al., 2013). Accordingly, in this study Epo was directly administrated in the LC area, and subsequently the hypercapnic ventilation was evaluated. Our results showed for the first time that Epo decreases the ventilatory response to $\mathrm{CO}_{2}$ by a direct modulation of LC neurons. Importantly, sham operated animals were not used in this work, since previous studies including a sham group did not show differences in basal ventilation and body temperature (Barros et al., 1998; Pokorski and Antosiewicz, 2010).

Concerning the mechanisms regulating the decreased $\mathrm{CO}_{2}$ stimulation of ventilation in rats treated with Epo, it is important to recall that besides the cells controlling respiratory rhythmogenesis, it is known that neighboring catecholaminergic groups increase inhibitory or decrease stimulatory inputs in the brainstem (Blanchi et al., 2003). In keeping with this, it was found that catecholaminergic cells are crucial regulators of ventilation upon hypoxic and hypercapnic stimulation, but not under basal ventilation (which is usually stable) (Hilaire et al., 2004; Soliz et al., 2005; Soulage et al., 2004, 2003). This observation is in line with our previous studies (performed in Epo transgenic mice lines) showing that Epo, by modulation of the catecholaminergic content, contribute to alter the HVR, while no differences were observed in basal ventilation (Caravagna et al., 2015; Soliz et al., 2005, 2007). Moreover, it was shown that higher NE content in A5, but lower NE content in $\mathrm{A} 2 \mathrm{C} 2$ and $\mathrm{A} 1 \mathrm{C} 1$ are associated with augmentation of the ventilation (Champagnat et al., 1979; Dick and Coles, 2000; Hilaire and Duron, 1999). In fact, in the opposite way, local application of NE within the A5 (simulating the impact of A6 over A5), silence the A5 neurons (by reducing the own secretion of $\mathrm{NE}$ ) and increase the frequency of the respiratory rhythm generator (Hilaire et al., 2004). As such, as the noradrenergic cells groups A6 and A5 have an opposite and complex influence of the respiratory rhythm generator, and our results show that Epo attenuates the ventilatory response to $\mathrm{CO}_{2}$, it is tempting to suggest that the NE content in $\mathrm{A} 5$ is reduced due to a direct influence of A6 cells. This speculation is in line with previous data showing that Epo modulates the release of catecholamines in brainstem areas (Soliz et al., 2005), and in brain slices (Yamamoto et al., 2000). In future experiments in vitro electrophysiological recordings and immunohistological studies might be performed to prove this hypothesis.

Interestingly, after re-evaluating the respiratory recording $24 \mathrm{~h}$ later from the first challenge, we observed that the HcVR in vehicletreated animals decreased, while the HcVR in Epo-injected animals was maintained in comparison to the corresponding first response. This result might be explained by the fact that microinjections produce micro-injures in the surroundings areas, thus producing cell dead and/or inflammation. As Epo is a neuroprotective factor with anti-cytotoxic, anti-apoptotic and anti-inflammatory properties (Wang et al., 2014), further decrease of the HcVR is not observed in the Epo-treated group.

In conclusion, our results show that cerebral Epo modulates the activity of LC neurons. Moreover, we showed that Epo in the LC attenuates the ventilatory response to increased levels of $\mathrm{PCO}_{2}$, and it may also protect the LC from the microinjection-induced injuries in the surrounding cells. As Epo is currently widely used in clinics for its therapeutic benefits in the brain, our results are relevant to better understand the Epo clinical implications in the respiratory responses evoked under basal and pathological conditions. 


\section{Conflict of interest}

There is no conflict of interest for any of the authors.

\section{Acknowledgments}

The authors wish to thank to Richard Kinkead, Daniela Furrer and Elizabeth Eliot-Portal for their appraisal of the manuscript and editorial assistance. Luciane Gargaglioni is supported by the Fundação de Amparo a Pesquisa do Estado de São Paulo (FAPESP 2012/19966-0), Conselho Nacional de Desenvolvimento Científico e Tecnológico (CNPq - 442560/2014-1). Jorge Soliz is funded by the Canadian Institutes of health Research and the "Fonds de recherche du Québec-Santé" (FRQ-S). The authors wish to thank to Euclides Seccato for his technical assistance.

\section{References}

Ballot, O., Joseph, V., Soliz, J., 2015a. Endogenous brain erythropoietin is a potent sex-specific respiratory stimulant in adult and newborn mice. J. Appl. Physiol. 1985, jap 0014302015.

Ballot, O., Laouafa, S., Elliot-Portal, E., Tam, R., Voituron, N., Joseph, V., Soliz, J., 2015b. The central chemosensitivity is not altered by cerebral erythropoietin. Neurosci. Lett. 609, 63-68.

Barros, R.C., Oliveira, E.S., Rocha, P.L., Branco, L.G., 1998. Respiratory and metabolic responses of the spiny rats Proechimys yonenagae and P. iheringi to CO2. Respir. Physiol. 111, 223-231.

Berridge, C.W., Waterhouse, B.D., 2003. The locus coeruleus-noradrenergic system: modulation of behavioral state and state-dependent cognitive processes. Brain Res. Brain Res. Rev. 42, 33-84.

Biancardi, V., Bicego, K.C., Almeida, M.C., Gargaglioni, L.H., 2008. Locus coeruleus noradrenergic neurons and $\mathrm{CO} 2$ drive to breathing. Pflug. Arch.: Eur. J. Physiol. 455, 1119-1128

Blanchi, B., Kelly, L.M., Viemari, J.C., Lafon, I., Burnet, H., Bevengut, M., Tillmanns, S., Daniel, L., Graf, T., Hilaire, G., Sieweke, M.H., 2003. MafB deficiency causes defective respiratory rhythmogenesis and fatal central apnea at birth. Nat. Neurosci. 6, 1091-1100

Brines, M.L., Ghezzi, P., Keenan, S., Agnello, D., de Lanerolle, N.C., Cerami, C., Itri, L.M., Cerami, A., 2000. Erythropoietin crosses the blood-brain barrier to protect against experimental brain injury. Proc. Natl. Acad. Sci. U. S. A. 97, 10526-10531.

Caravagna, C., Soliz, J., 2015. PI3K and MEK1/2 molecular pathways are involved in the erythropoietin-mediated regulation of the central respiratory command. Respir. Physiol. Neurobiol. 206, 36-40.

Caravagna, C., Kinkead, R., Soliz, J., 2014. Post-natal hypoxic activity of the central respiratory command is improved in transgenic mice overexpressing Epo in the brain. Respir. Physiol. Neurobiol. 200, 64-71.

Caravagna, C., Schneider-Gasser, E.M., Ballot, O., Joseph, V., Soliz, J., 2015. Chronic overexpression of cerebral Epo improves the ventilatory response to acute hypoxia during the postnatal development. Int. J. Dev. Neurosci. 44, 84-91.

Champagnat, J., Denavit-Saubie, M., Henry, J.L., Leviel, V., 1979. Catecholaminergic depressant effects on bulbar respiratory mechanisms. Brain Res. 160, 57-68.

de Carvalho, D., Patrone, L.G., Taxini, C.L., Biancardi, V., Vicente, M.C., Gargaglioni, L.H., 2014. Neurochemical and electrical modulation of the locus coeruleus: contribution to CO2drive to breathe. Front. Physiol. 5, 288.

Dick, T.E., Coles, S.K., 2000. Ventrolateral pons mediates short-term depression of respiratory frequency after brief hypoxia. Respir. Physiol. 121, 87-100.

Filosa, J.A., Dean, J.B., Putnam, R.W., 2002. Role of intracellular and extracellular pH in the chemosensitive response of rat locus coeruleus neurones. J. Physiol. 541, 493-509.

Foote, S.L., Bloom, F.E., Aston-Jones, G., 1983. Nucleus locus ceruleus: new evidence of anatomical and physiological specificity. Physiol. Rev. 63, 844-914.

Gargaglioni, L.H., Hartzler, L.K., Putnam, R.W., 2010. The locus coeruleus and central chemosensitivity. Respir. Physiol. Neurobiol. 173, 264-273.

Guyenet, P.G., Stornetta, R.L., Bayliss, D.A., 2010. Central respiratory chemoreception. J. Comp. Neurol. 518, 3883-3906.
Hilaire, G., Duron, B., 1999. Maturation of the mammalian respiratory system. Physiol. Rev. 79, 325-360.

Hilaire, G., Viemari, J.C., Coulon, P., Simonneau, M., Bevengut, M., 2004. Modulation of the respiratory rhythm generator by the pontine noradrenergic A5 and A6 groups in rodents. Respir. Physiol. Neurobiol. 143, 187-197.

Khemiri, H., Seaborn, T., Gestreau, C., Soliz, J., 2011. Erythropoietin and soluble erythropoietin receptor regulate the neural control of hypoxic respiration in newborn mice. Respir. Physiol. Neurobiol. 183, 151-121.

Kumar, N.N., Velic, A., Soliz, J., Shi, Y., Li, K., Wang, S., Weaver, J.L., Sen, J., Abbott, S.B., Lazarenko, R.M., Ludwig, M.G., Perez-Reyes, E., Mohebbi, N., Bettoni, C., Gassmann, M., Suply, T., Seuwen, K., Guyenet, P.G., Wagner, C.A., Bayliss, D.A., 2015. Regulation of breathing by CO2 requires the proton-activated receptor GPR4 in retrotrapezoid nucleus neurons. Science 348, 1255-1260.

Oyamada, Y., Ballantyne, D., Muckenhoff, K., Scheid, P., 1998. Respiration-modulated membrane potential and chemosensitivity of locus coeruleus neurones in the in vitro brainstem-spinal cord of the neonatal rat. J. Physiol. 513 (Pt. 2), 381-398.

Paxinos, G., Watson, C., 1998. The Brain in Stereotaxic Coordinates, 4th ed. Academic, San Diego, CA.

Pineda, J., Aghajanian, G.K., 1997. Carbon dioxide regulates the tonic activity of locus coeruleus neurons by modulating a proton- and polyamine-sensitive inward rectifier potassium current. Neuroscience 77, 723-743.

Pokorski, M., Antosiewicz, J., 2010. Alterations in the hypoxic ventilatory response with advancing age in awake rats. J. Physiol. Pharmacol. 61, 227-232.

Rabie, T., Marti, H.H., 2008. Brain protection by erythropoietin: a manifold task. Physiology (Bethesda) 23, 263-274.

Saiki, C., Mortola, J.P., 1996. Effect of $\mathrm{CO} 2$ on the metabolic and ventilatory responses to ambient temperature in conscious adult and newborn rats. J. Physiol. 491 (Pt. 1), 261-269.

Samuels, E.R., Szabadi, E., 2008. Functional neuroanatomy of the noradrenergic locus coeruleus: its roles in the regulation of arousal and autonomic function part I: principles of functional organisation. Curr. Neuropharmacol. 6, 235-253.

Santin, J.M., Hartzler, L.K., 2013. Respiratory signaling of locus coeruleus neurons during hypercapnic acidosis in the bullfrog, Lithobates catesbeianus. Respir. Physiol. Neurobiol. 185, 553-561.

Soliz, J., Joseph, V., Soulage, C., Becskei, C., Vogel, J., Pequignot, J.M., Ogunshola, O., Gassmann, M., 2005. Erythropoietin regulates hypoxic ventilation in mice by interacting with brainstem and carotid bodies. J. Physiol. 568, 559-571.

Soliz, J., Soulage, C., Hermann, D.M., Gassmann, M., 2007. Acute and chronic exposure to hypoxia alters ventilatory pattern but not minute ventilation of mice overexpressing erythropoietin. Am. J. Physiol. Regul. Integr. Comp. Physiol. 293, R1702-R1710.

Soliz, J., Thomsen, J., Soulage, C., Lundby, C., Gassmann, M., 2009. Sex-dependent regulation of hypoxic ventilation in mouse and man is mediated by erythropoietin. Am. J. Physiol. Regul. Integr. Comp. Physiol. 296, R1837-1846.

Soulage, C., Perrin, D., Cottet-Emard, J.M., Pequignot, J.M., 2003. A6 noradrenergic cell group modulates the hypoxic ventilatory response. Adv. Exp. Med. Biol. 536, 481-487.

Soulage, C., Pascual, O., Roux, J.C., Denavit-Saubie, M., Pequignot, J.M., 2004. Chemosensory inputs and neural remodeling in carotid body and brainstem catecholaminergic cells. Adv. Exp. Med. Biol. 551, 53-58.

Swanson, L.W., Hartman, B.K., 1975. The central adrenergic system. An immunofluorescence study of the location of cell bodies and their efferent connections in the rat utilizing dopamine-beta-hydroxylase as a marker. J. Comp. Neurol. 163, 467-505.

Taxini, C.L., Puga, C.C., Dias, M.B., Bicego, K.C., Gargaglioni, L.H., 2013. Ionotropic but not metabotropic glutamatergic receptors in the locus coeruleus modulate the hypercapnic ventilatory response in unanaesthetized rats. Acta Physiol. (Oxf.) 208, 125-135.

Vicente, M.C., Dias, M.B., Fonseca, E.M., Bicego, K.C., Gargaglioni, L.H., 2016. Orexinergic system in the locus coeruleus modulates the $\mathrm{CO} 2$ ventilatory response. Pflug. Arch.: Eur. J. Physiol. 468, 763-774.

Wang, L., Di, L., Noguchi, C.T., 2014. Erythropoietin, a novel versatile player regulating energy metabolism beyond the erythroid system. Int. J. Biol. Sci. 10, 921-939.

Yamamoto, M., Koshimura, K., Kawaguchi, M., Sohmiya, M., Murakami, Y., Kato, Y., 2000. Stimulating effect of erythropoietin on the release of dopamine and acetylcholine from the rat brain slice. Neurosci. Lett. 292, 131-133. 